\title{
Thermal Model Predictions of Advanced Stirling Radioisotope Generator Performance
}

\author{
Xiao-Yen J. Wang ${ }^{1}$ and William A. Fabanich ${ }^{2}$ \\ NASA Glenn Research Center, Cleveland, Ohio, 44135 \\ and \\ Paul C. Schmitz ${ }^{3}$ \\ Power Computing Solutions, Inc. \\ Cleveland, Ohio, 44135
}

\begin{abstract}
This paper presents recent thermal model results of the Advanced Stirling Radioisotope Generator (ASRG). The three-dimensional (3D) ASRG thermal power model was built using the Thermal Desktop® thermal analyzer. The model was correlated with ASRG engineering unit test data and ASRG flight unit predictions from Lockheed Martin's (LM's) I-deas ${ }^{\mathrm{TM}}$ TMG thermal model. The auxiliary cooling system (ACS) of the ASRG is also included in the ASRG thermal model. The ACS is designed to remove waste heat from the ASRG so that it can be used to heat spacecraft components. The performance of the ACS is reported under nominal conditions and during a Venus flyby scenario. The results for the nominal case are validated with data from Lockheed Martin. Transient thermal analysis results of ASRG for a Venus flyby with a representative trajectory are also presented. In addition, model results of an ASRG mounted on a Cassini-like spacecraft with a sunshade are presented to show a way to mitigate the high temperatures of a Venus flyby. It was predicted that the sunshade can lower the temperature of the ASRG alternator by $20{ }^{\circ} \mathrm{C}$ for the representative Venus flyby trajectory. The 3D model also was modified to predict generator performance after a single Advanced Stirling Convertor failure. The geometry of the Microtherm HT insulation block on the outboard side was modified to match deformation and shrinkage observed during testing of a prototypic ASRG test fixture by LM. Test conditions and test data were used to correlate the model by adjusting the thermal conductivity of the deformed insulation to match the post-heat-dump steady state temperatures. Results for these conditions showed that the performance of the still-functioning inboard ACS was unaffected.
\end{abstract}

\section{Introduction}

The Advanced Stirling Radioisotope Generator (ASRG) in Refs. 1-2 is being developed for multimission applications to provide a high-efficiency power source alternative to Multi-Mission Radioisotope Thermoelectric Generators (MMRTGs). The higher ASRG efficiency reduces the required amount of radioisotope by roughly a factor of 4 in comparison to an MMRTG. The ASRG could address the limited supply of Pu-238 by extending the radioisotope power available for future space science missions - such as deep-space missions, large planetary surface rovers, and other systems in support of human exploration activities.

Figure 1 shows an overview of the ASRG and its interface with the spacecraft (SC). It consists of two advanced Stirling convertors (ASCs) enclosed within a housing. Each ASC has a General Purpose Heat Source (GPHS) coupled to its hot end. Heat is removed from the ASC and travels through the Cold Side Adapter Flange (CSAF) to the housing. The housing and its attached fins radiate heat to the environment. Argon cover gas is contained within the sealed housing until the ASRG is launched to ensure that there is no interaction between the hot components and air. After launch, the gas management valve ensures that the argon is permanently vented to vacuum. The ASC controller unit is remotely located from the ASRG

\footnotetext{
${ }^{1}$ Aerospace Engineer, Thermal Systems Branch, 21000 Brookpark Rd./MS 86-12, AIAA member.

2 Aerospace Engineer, Thermal Systems Branch, 21000 Brookpark Rd./MS 86-12.

${ }^{3}$ Aerospace Engineer, Power Computing Solutions, Inc., 21000 Brookpark Rd./MS 301-2.
} 
housing and is connected to it via an interconnect cable. It converts the alternating-current (AC) output from both ASCs to 22 to 36 volts direct current $\left(\mathrm{V}_{\mathrm{DC}}\right)$ for a typical SC electrical bus. The controller is used to maintain synchronized displacer/piston movement of the two directionally opposed Stirling convertors to minimize induced disturbance to the SC and any precision instrumentation.

An ASC consists of a free-piston Stirling convertor and an integral linear alternator that converts the piston reciprocating motion to electrical power output. The Stirling engine is a heat engine that operates by cyclic compression and expansion of a working fluid at different temperature levels such that there is net conversion of heat energy to mechanical work. The GPHS provides the heat to the heater head of the ASC. Helium, which is used as the working fluid, is hermetically sealed within the convertor pressure vessel. The displacer shuttles helium between the expansion space, where heat is received, and the compression space, where the heat is rejected at the CSAF attached to the housing. The changes in the pressures and volumes of the convertor working spaces drive a power piston that reciprocates and, when attached to the permanent-magnet linear alternator, produces single-phase $\mathrm{AC}$ electrical power.

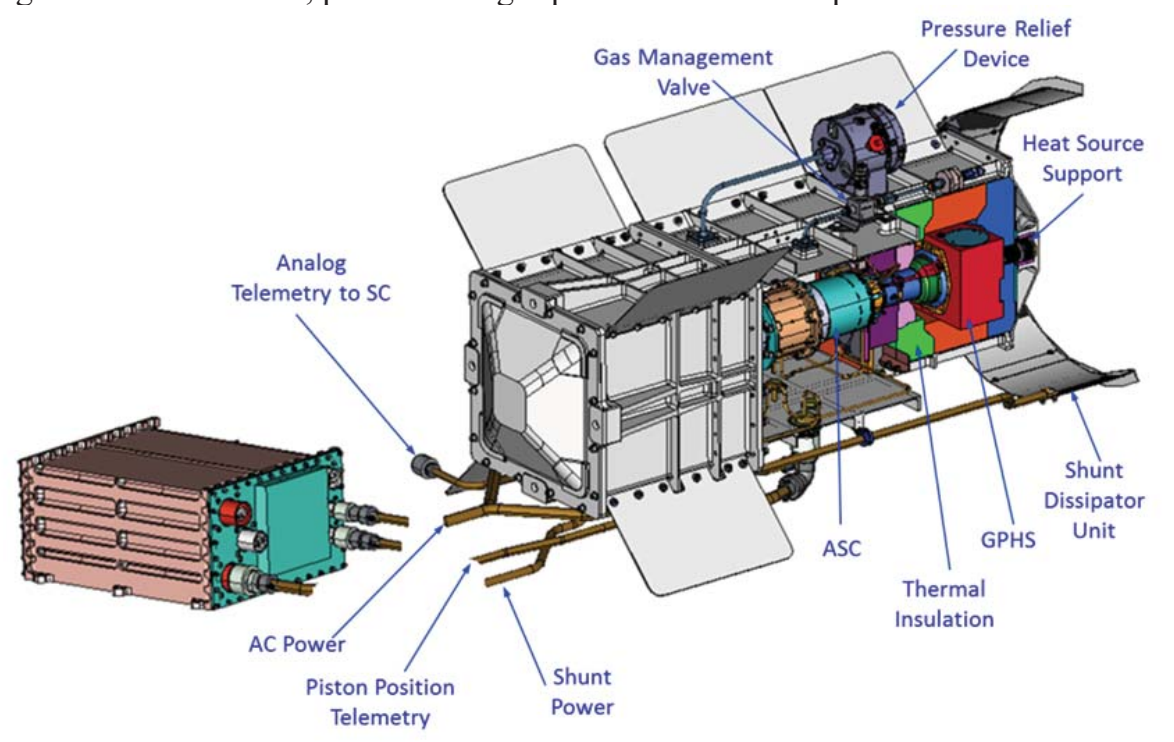

Figure 1. Overview of Advanced Stirling Radioisotope Generator components.

Thermal Desktop (TD) was used to build a 3D steady-state thermal power model to predict the ASRG AC power output under different operating conditions [3]. The model was validated with Lockheed Martin (LM) model-predicted results for flight unit and testing data for the engineering unit (EU). This work presents some of the new features and capabilities that were added to the thermal model described in Ref. 3. The main areas of focus are the performance of the auxiliary cooling system (ACS) [4], which is designed to remove the ASRG waste heat and deliver it to the SC for other uses; the transient analysis of a Venus flyby case; and the simulation of an ASRG with one failed ASC. The ACS performance for both the nominal case and Venus flyby scenario was predicted. A representative trajectory for a Venus flyby was used for the transient analysis, and the results are presented and discussed. A Cassini-like SC with an ASRG and sunshade was modeled to investigate the concept of using a sunshade to mitigate the effects of the extremely hot environment of a Venus flyby. In the following sections, the ACS performance is reported first, followed by the Venus flyby transient analysis results and ASRG performance after the failure of one ASC.

\section{Auxiliary Cooling System Performance Prediction}

The baseline design of the ACS is a pumped fluid loop that goes through two sides of the ASRG housing and is attached to the housing near the CSAF by block heat exchangers. For a given fluid inlet condition (volume flow rate and temperature), the thermal model computes how much heat the fluid removes from the ASRG housing while the ASRG is operating. Figure 2 shows the temperature of the ASRG housing and the fluid temperature along the loop of the ACS assuming that the ASRG is operating at the nominal case: that is, the ASC hot end temperature $\left(T_{h}\right)$ is $760{ }^{\circ} \mathrm{C}$ in a $4 \mathrm{~K}$ sink temperature 
environment and with a 244-W GPHS. For this case, the total amount of waste heat from the two loops is $23.3 \mathrm{~W}$ and the cold-end temperature $\left(T_{c}\right)$ of the ASC decreases by $8{ }^{\circ} \mathrm{C}$. Different sink and fluid inlet temperatures were studied for the same $T_{h}$ and GPHS heat input for the ASRG. The direct current (DC) power output versus waste heat recovery as a function of fluid temperature and sink temperature is plotted in Fig. 3, which shows that the DC power output is a linear function of the waste heat extracted by the ACS. A similar trend is shown in LM's predictions.
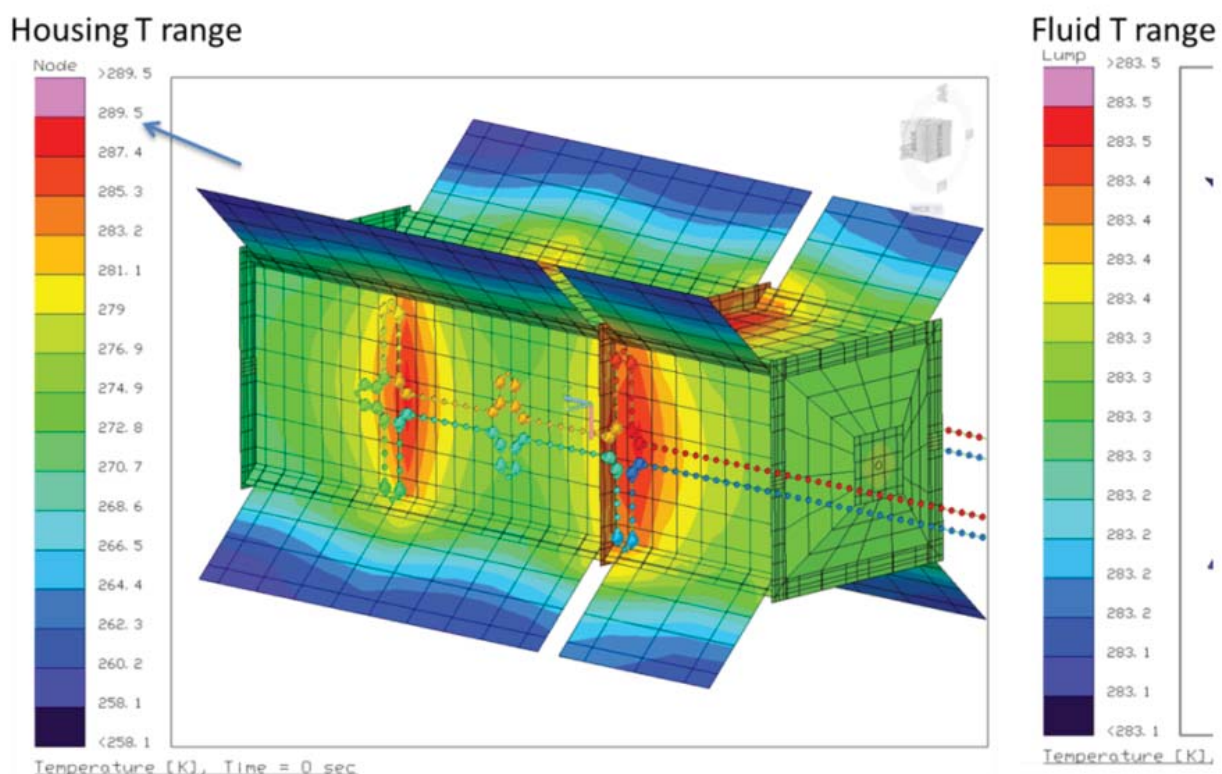

Figure 2. Advanced Stirling Radioisotope Generator housing temperature and fluid temperature for nominal case.

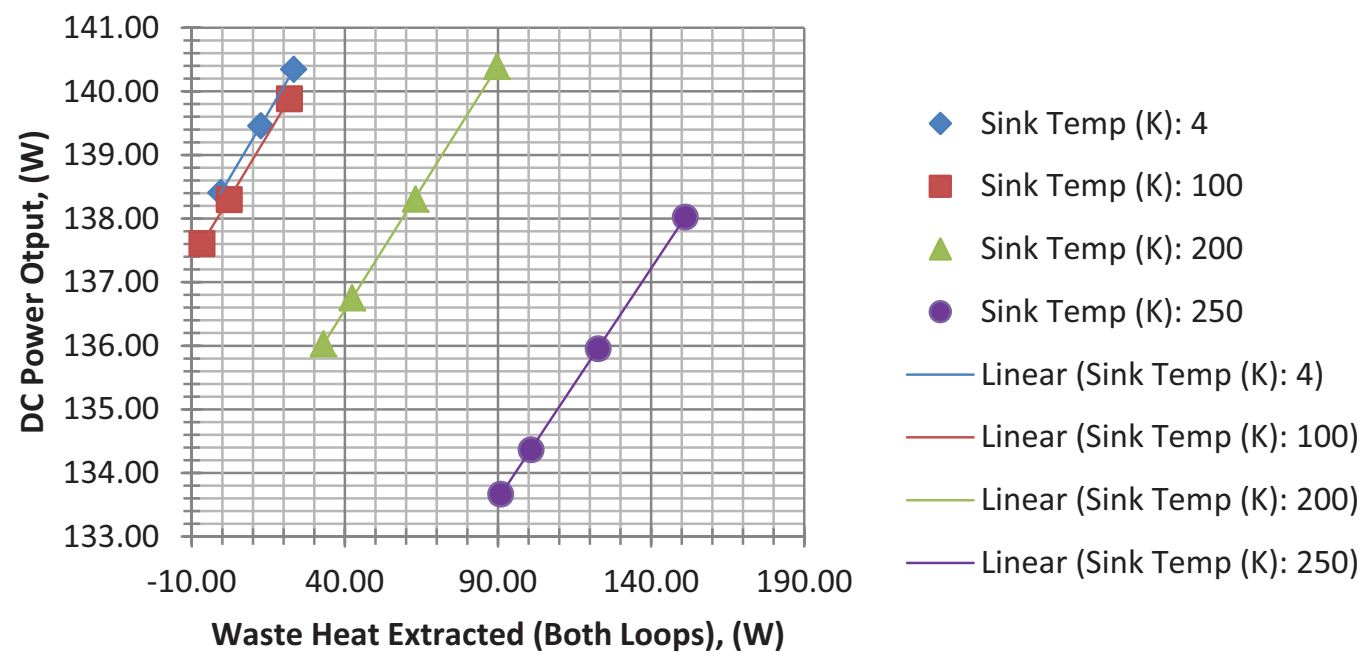

Figure 3. Advanced Stirling Radioisotope Generator direct current power output as a function of waste heat extracted for different sink temperatures.

For the ASRG Venus flyby scenario, the SC can come as close as $300 \mathrm{~km}$ from the surface (approximately low Earth orbit altitudes). The enviroment is very hot, and the ASRG temperature needs to be verified to ensure that it does not violate its high temperature limit. During this period of time, the direct solar radiation (for an orbit of $0.7 \mathrm{AU}$ ) is approximately $2588 \mathrm{~W} / \mathrm{m}^{2}$, the reflected solar energy from Venus (albedo $=0.72$ ) is $1900 \mathrm{~W} / \mathrm{m}^{2}$, and the infrared (IR) radiated energy from Venus (Venus as the thermal 
source) is $120 \mathrm{~W} / \mathrm{m}^{2}$. As the first step, steady-state analysis was performed for the worst case with a solar absorptivity of 0.16 for the Z93 paint. As shown in Fig. 4, the worst orientation of the ASRG-toward the Sun - was considered: that is, two sides of the ASRG housing face directly toward the Sun, and the other two sides face toward Venus. The temperature of the ASRG housing is plotted in Fig. 5 for the Venus flyby scenario with the ASRG operating at $T_{h}=760{ }^{\circ} \mathrm{C}$. The cold-end temperature of the ASC reaches $100{ }^{\circ} \mathrm{C}$ $(373 \mathrm{~K})$, an increase of $60{ }^{\circ} \mathrm{C}$ from the case for a $4 \mathrm{~K}$ sink temperature environment.

If the ACS is functioning, the ASC cold-end temperature can drop to $330.4 \mathrm{~K}$, and $189.4 \mathrm{~W}$ waste heat can be removed from the ASRG housing. The results show that the ACS can provide heat to help maintain $\mathrm{SC}$ electronic boxes within temperature limits. This heat would otherwise be provided by electrical heaters that would require additional battery mass.

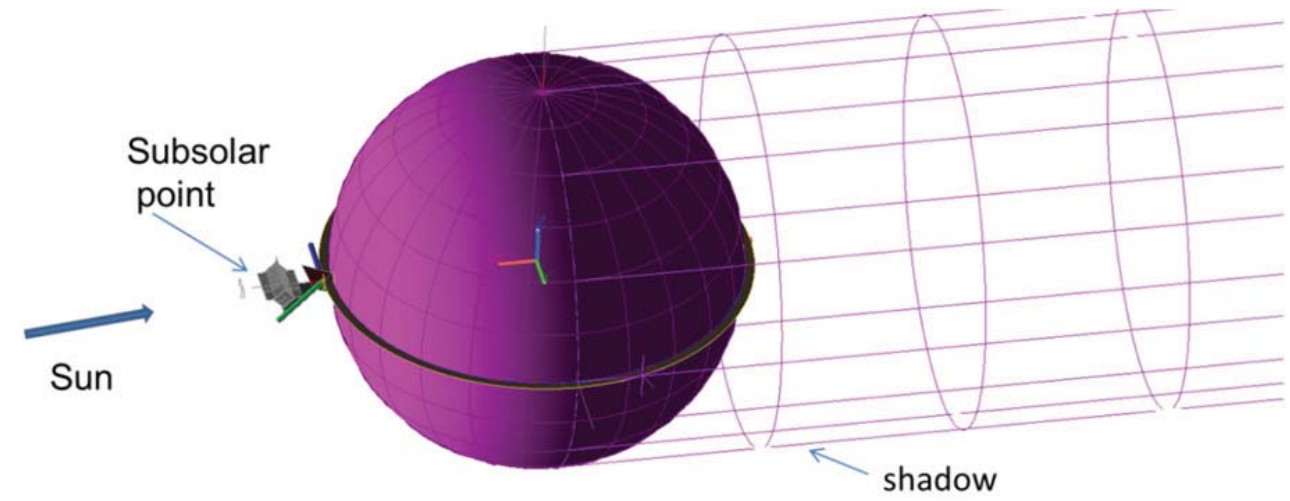

Figure 4. One position on Venus flyby trajectory.
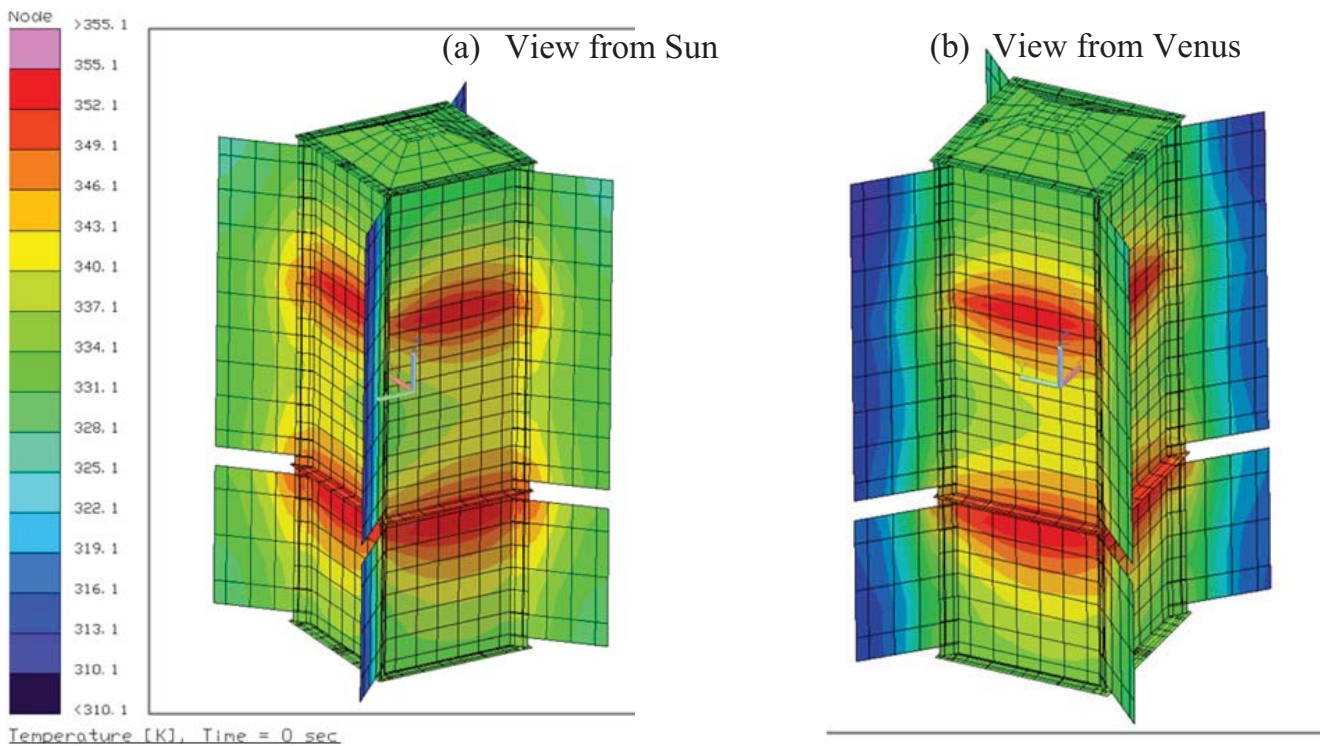

Figure 5. Temperature of Advanced Stirling Radioisotope Generator housing for Venus flyby (auxiliary cooling system is turned off).

\section{Transient Analysis of Advanced Stirling Radioisotope Generator Venus Flyby}

For the transient analysis, a representative trajectory is defined in TD/SINDA/FLUINT and five positions are plotted in Fig. 6, showing the time and altitudes. The trajectory lasts almost 2 hours, and the ASRG reaches the minimum altitude at time $t=60 \mathrm{~min}$ at the same location described in Section II for the steady-state analysis. The ASRG does not articulate during the trajectory. The heat flux from the 
environment is shown in Fig. 7 (a)-(e) at five positions on the trajectory. The equivalent sink temperatures for the sides of the ASRG housing facing the Sun and the sides facing Venus are plotted in Fig. 7(f), showing that the sides of the housing that faced the Sun were exposed to similar solar fluxes along the entire trajectory and that the sides of the housing that faced Venus received dramatically changing albedo and IR radiation from Venus.

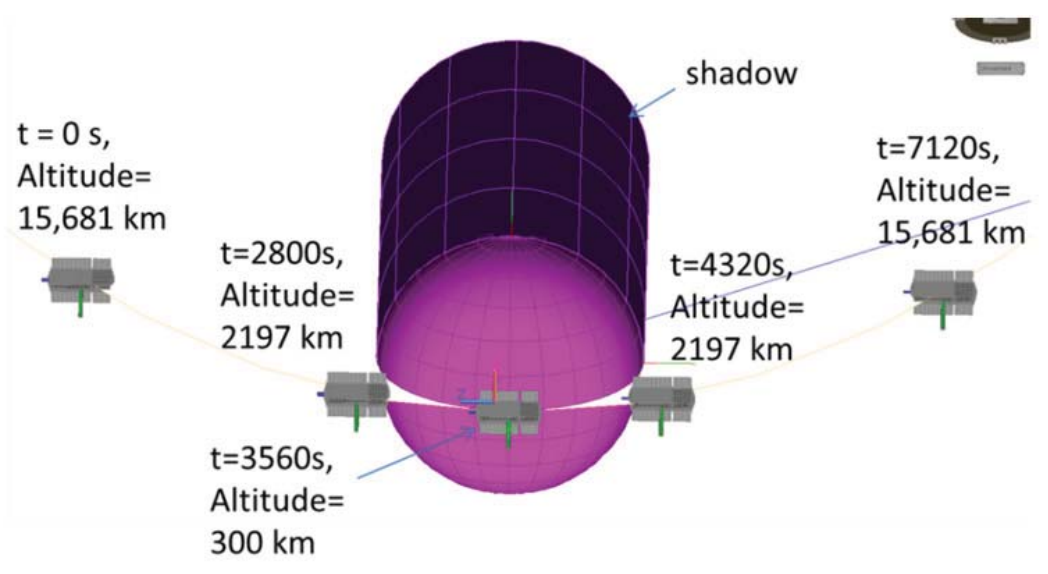

Figure 6. Venus flyby trajectory (viewed from Sun).

In the transient thermal model, the thermal mass and specific heat for each component were updated on the basis of data from the LM report, and the ASC represented by the SAGE-generated map was updated at every time step. The ASRG control strategy was to maintain constant piston amplitude instead of constant $T_{h}$, and the transient solver in TD/SINDA-FLUINT was used.

The transient thermal model results are plotted in Fig. 8 at different times on the trajectory. It can be seen that the ASRG gets warmer as it approaches the minimum altitude above Venus. The initial conditions for the transient analysis were defined using the steady-state solution at the starting position on the trajectory, which is identical to the steady-state solution when the ASRG is on a Sun orbit of $0.72 \mathrm{AU}$. For both the steady-state and transient analysis, a constant piston amplitude of $4.5 \mathrm{~mm}$ was used. For the $4 \mathrm{~K}$ vacuum condition, $T_{h}=742.3{ }^{\circ} \mathrm{C}, T_{c}=40^{\circ} \mathrm{C}$, and DC power $=84.3 \mathrm{~W}$ for one ASC, which is similar to the ASRG baseline that maintains $T_{h}=760{ }^{\circ} \mathrm{C}$.

Because the alternator temperature is the major concern of the temperature limit and is roughly $10{ }^{\circ} \mathrm{C}$ higher than $T_{c}$, the transient results of $T_{c}$ as it changed with time along the trajectory were plotted in Fig. 9 along with the $T_{c}$ changes predicted from the steady-state analysis. The steady-state results show that $T_{c}$ increased by $30{ }^{\circ} \mathrm{C}$ (the worst case), whereas the transient results show that $T_{c}$ increased by $10{ }^{\circ} \mathrm{C}$. The LM transient model predicted that the alternator temperature increased $\sim 27^{\circ} \mathrm{C}$ during a transient flyby.

From the current analysis results, we can predict that the alternator temperature should not increase as much as the worst case (an increase of $30{ }^{\circ} \mathrm{C}$ ). How much $T_{c}$ will increase during the flyby depends on the ASRG response time to the environmental temperature changes. Reference 5 shows some curves of $T_{h}$ and $T_{c}$ versus time when the environment changes from the launch pad conditions to a $4 \mathrm{~K}$ vacuum. On the basis of the curve, the estimated ASRG response time $(\tau)$ was roughly 48 min for the cold end. A sensitivity study of how $T_{c}$ changes for different $\tau$ was performed using Eq. (1), and the results are plotted in Fig. 10 for the $T_{c}$ increases defined in Eq. (2). The figure shows that $T_{c}$ increases $\sim 10{ }^{\circ} \mathrm{C}$ for $\tau=48 \mathrm{~min}, 12{ }^{\circ} \mathrm{C}$ for $\tau=30 \mathrm{~min}, 14{ }^{\circ} \mathrm{C}$ for $\tau=20 \mathrm{~min}, 21{ }^{\circ} \mathrm{C}$ for $\tau=10 \mathrm{~min}$, and $30^{\circ} \mathrm{C}$ for $\tau=0$ (steady-state case). For $\tau=48 \mathrm{~min}$, the $T_{c}$ increases are very close to the $3 \mathrm{D}$ TD transient result prediction.

$$
\begin{aligned}
\frac{d T_{c}}{d t} & =\frac{\left(T_{c}\right)_{\text {steady }}-T_{c}}{\tau} \\
\Delta T_{c} & =\left(T_{c}\right)_{\max }-\left(T_{c}\right)_{t=0}
\end{aligned}
$$



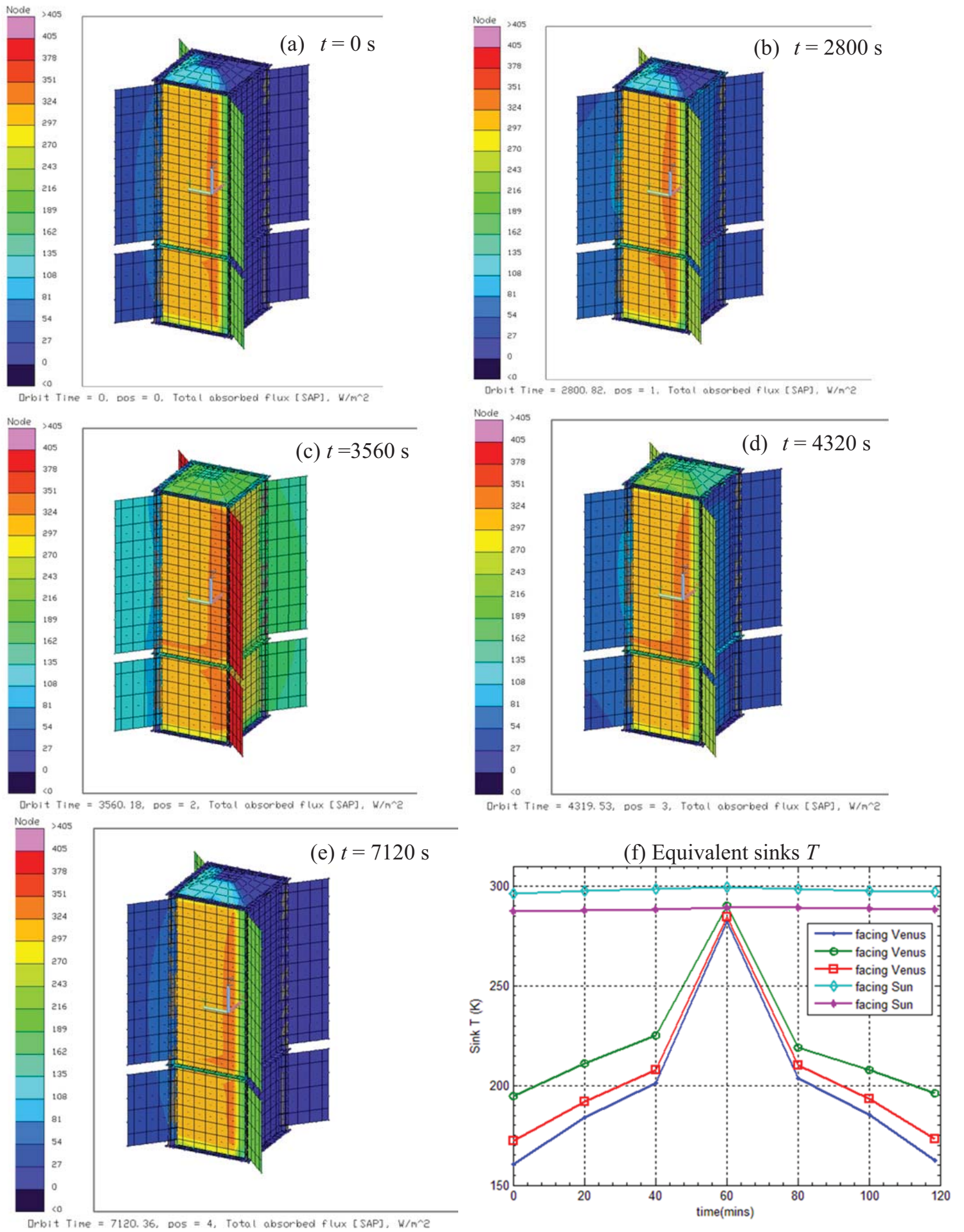

Figure 7. Total absorbed heat flux from environment at five positions on trajectory (a)-(e), and equivalent sink temperature (f). 

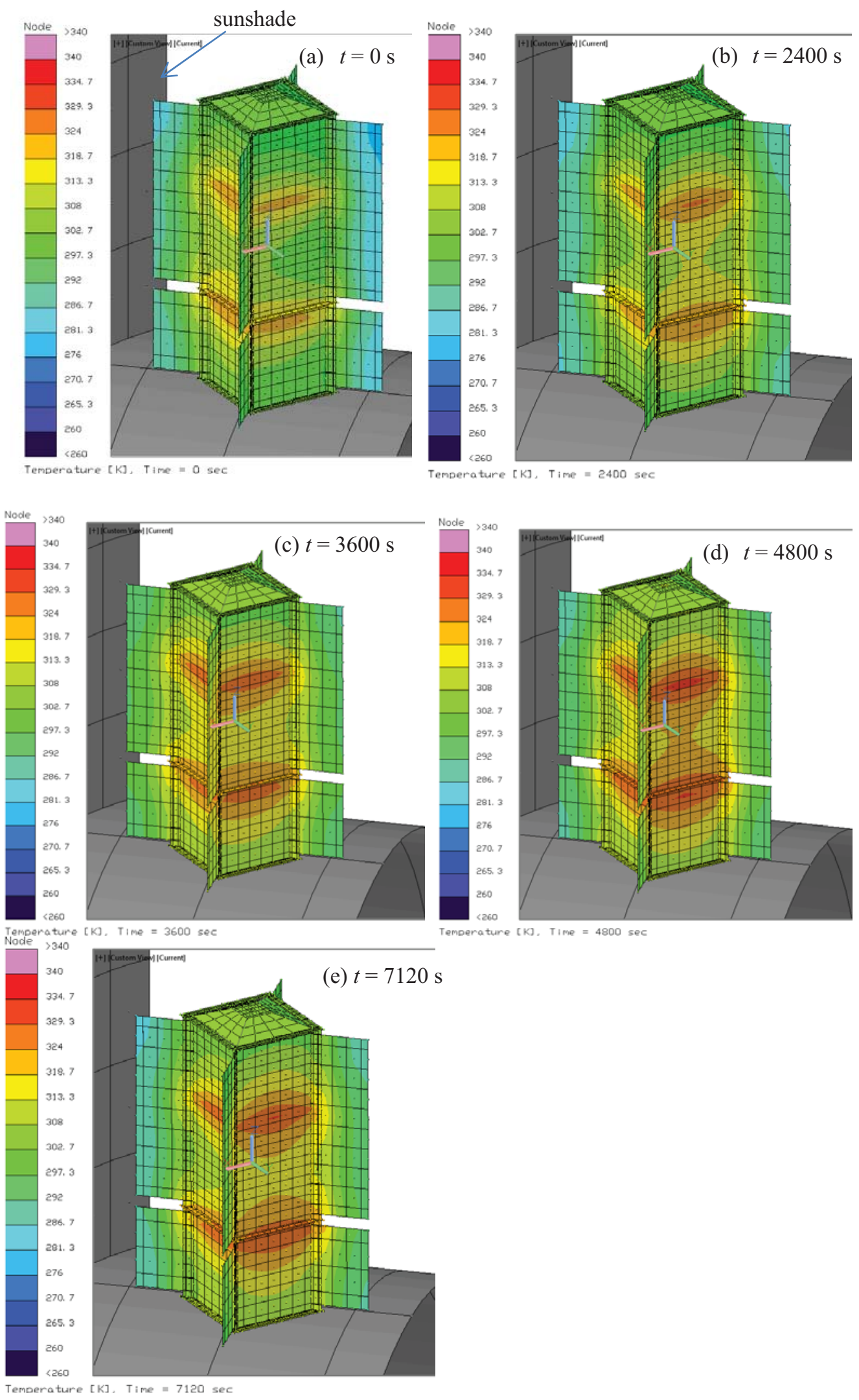

Figure 8. Thermal Desktop transient model results at different times on trajectory. 


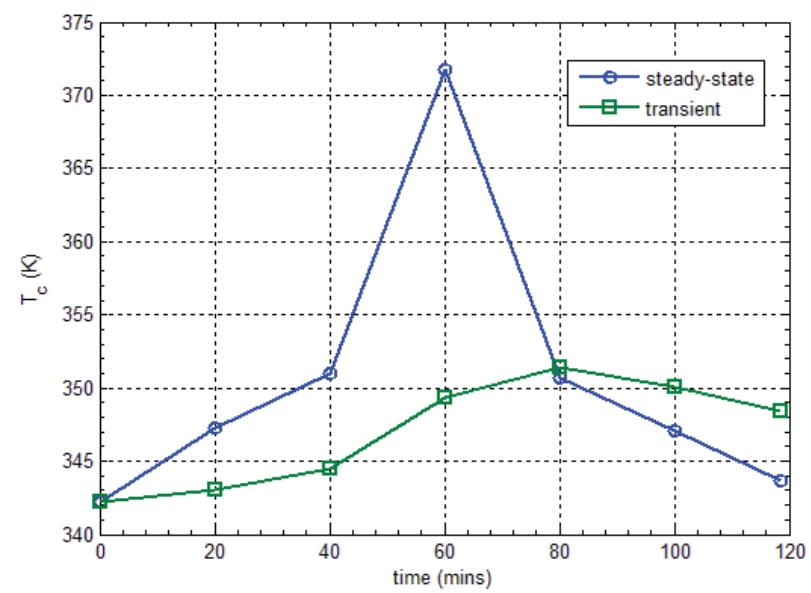

Figure 9. $T_{c}$ /Alternator temperature changes with time during flyby (steady-state and transient results).
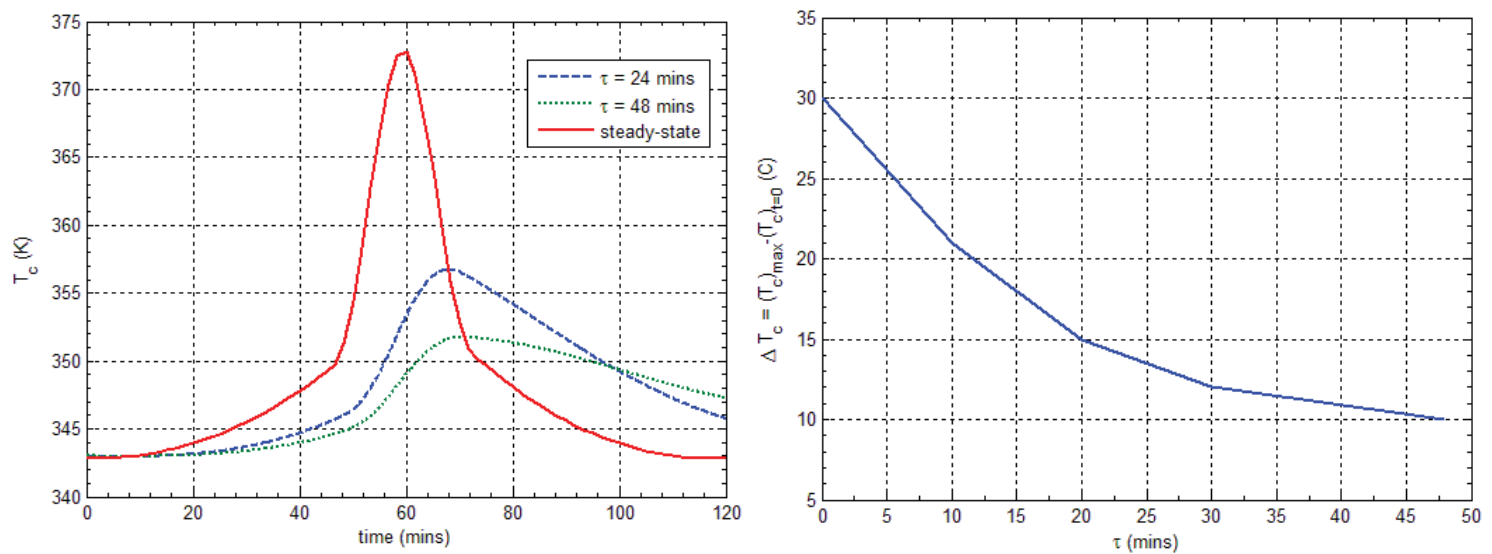

Figure 10. Sensitivity study of $T_{c}$ /alternator temperature for different ASRG response times $(\tau)$.

A Cassini-like SC, $2 \mathrm{~m}$ in diameter and $2 \mathrm{~m}$ in height, was modeled with a sunshade right in front of the ASRG, as shown in Fig. 8. The emissivity and solar absorptivity of the sunshade were assumed to be 0.88 and 0.1 for the side facing the Sun and 0.04 and 0.3 for the side insulated with a multilayer insulation blanket. For a $4 \mathrm{~K}$ vacuum condition, $T_{h}=738.1{ }^{\circ} \mathrm{C}, T_{c}=44.7^{\circ} \mathrm{C}$, and $\mathrm{DC}$ power $=83.4 \mathrm{~W}$ for one ASC with a sunshade and SC compared with $T_{h}=742.3{ }^{\circ} \mathrm{C}, T_{c}=40{ }^{\circ} \mathrm{C}$, and DC power $=84.3 \mathrm{~W}$ for one ASC without a sunshade and SC.

The corresponding equivalent sink temperature for the trajectory described earlier is plotted in Fig. 11, which shows that the housing facing the Sun becomes much cooler when the sunshade is used. The side of the housing facing Venus becomes warmer because of the interaction with the SC and sunshade. At the minimum altitude $(300 \mathrm{~km})$, the equivalent sink temperature is similar with and without the sunshade. The TD transient results are plotted in Fig. 12 at different times on the trajectory. The $T_{c}$ changes along the trajectory are plotted in Fig. 13 with those predicted from the steady-state analysis. It can be seen that the sunshade can reduce the cold end temperature by $\sim 22{ }^{\circ} \mathrm{C}$ at the starting position on the trajectory. The $T_{c}$ increase on the trajectory is approximately $15^{\circ} \mathrm{C}$. One interesting fact is observed from the steady-state results. At the minimum altitude of $300 \mathrm{~km}$, because the albedo and IR radiation have increased so much, the sunshade cannot really lower the ASRG temperature. Instead, $T_{c}$ is slightly higher than it is without the sunshade and SC because of the heat transfer between the SC, sunshade, and ASRG. 


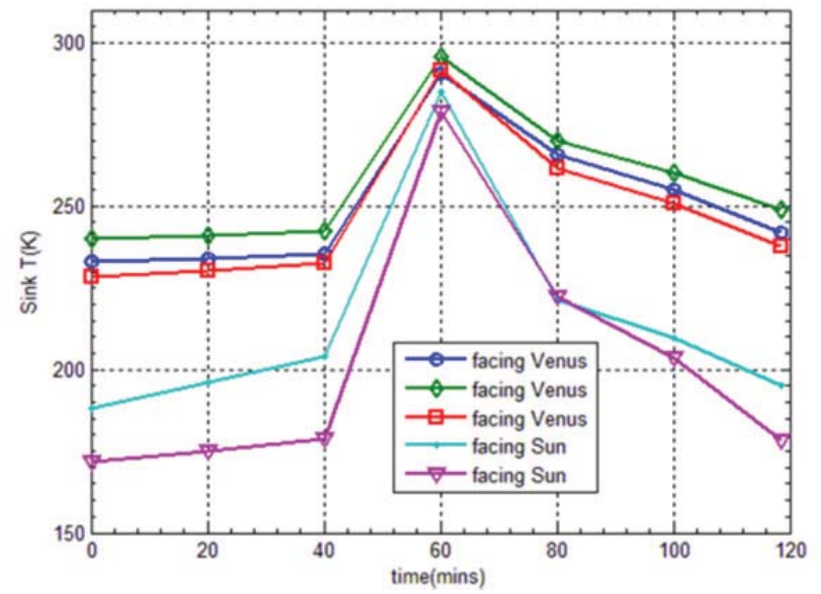

Figure 11. Equivalent sink temperatures along trajectory for Advanced Stirling Radioisotope Generator with spacecraft and sunshade.
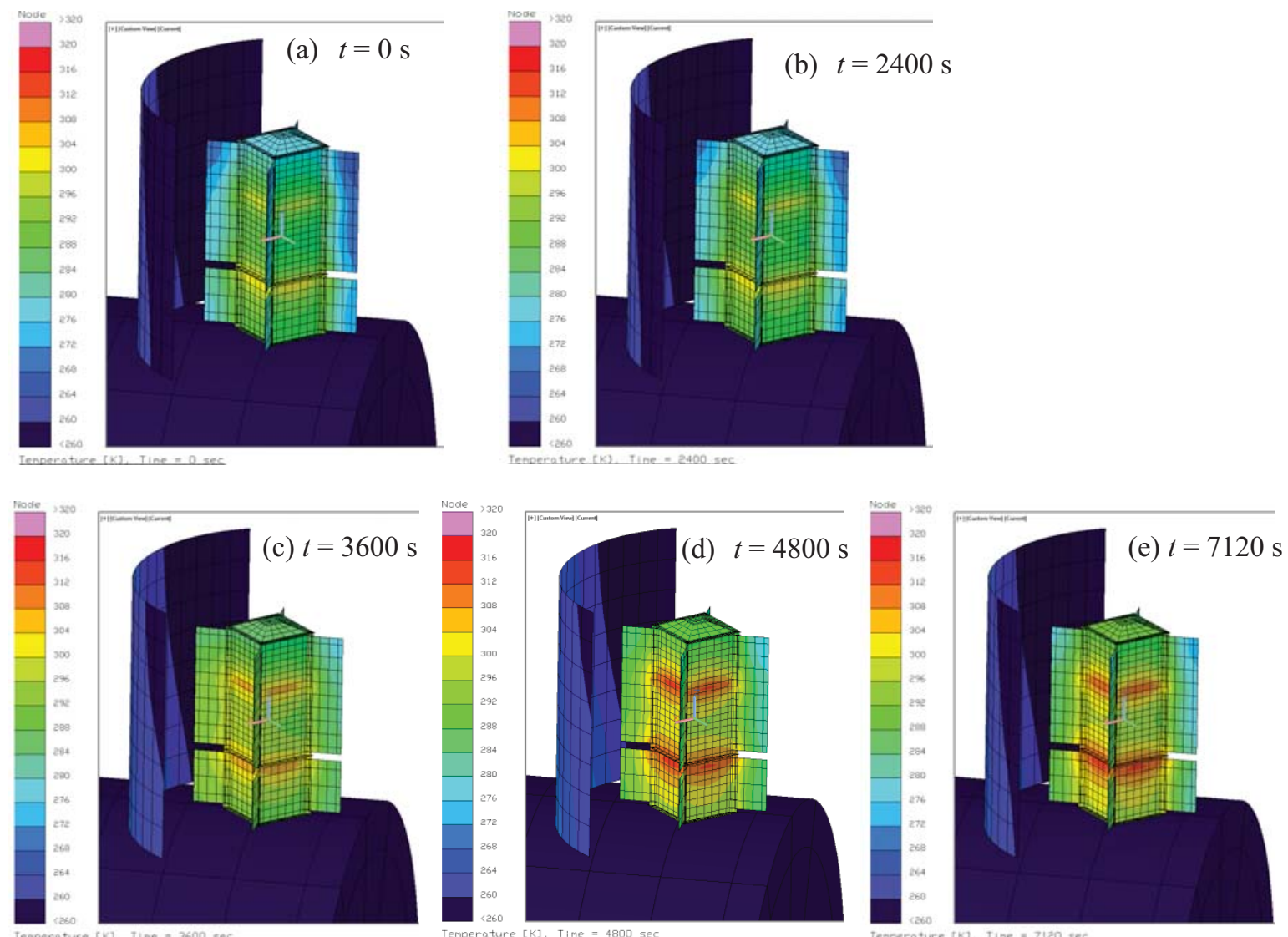

Figure 12. Thermal Desktop model transient results at different times on trajectory (with spacecraft and sunshade). 


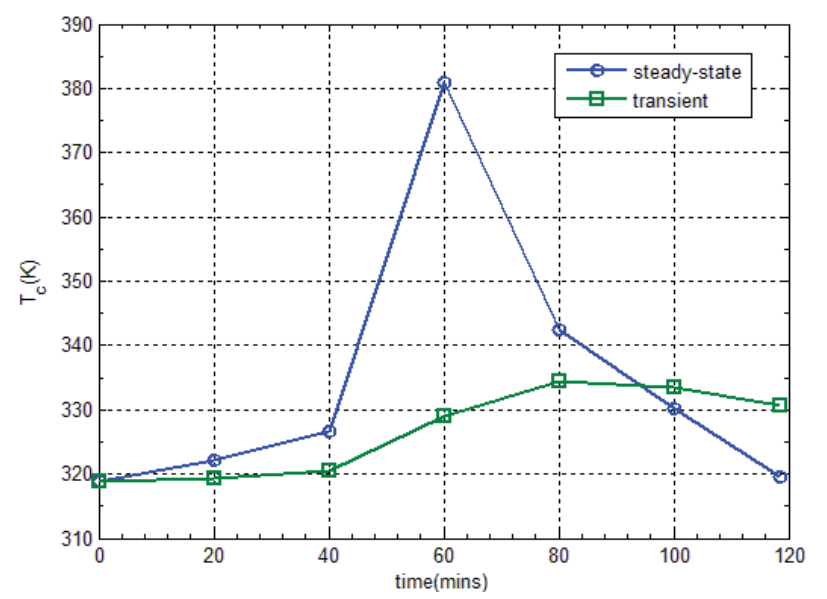

Figure 13. $T_{c}$ /Alternator temperature changes versus time for ASRG with sunshade and spacecraft during flyby.

\section{Emergency Heat Dump Modeling}

Lockheed Martin performed development testing of a prototypic ASRG to determine the effects of the failure of an ASC on the geometry and properties of the Microtherm HT insulation block. Here, a failure of the ASC results in addition heat that is no longer converted or rejected by the ASC now being conducted through the insulation block or the pre-loaded stud. This information was used to predict the performance of the generator after the heat dump, specifically the resulting power output of the remaining ASC [6]. The test also provided estimates of the temperatures of the fuel-clad GPHS to verify that the temperatures were maintained below the established nuclear safety requirements.

The test fixture simulated one end of the ASRG. It contained the insulation block and a simulated GPHS or electric heat source (EHS). The power input into the EHS was set to a level that accounted for losses specific to the test fixture and simulated the heat dissipation after an ASC failure. The insulation block deformed and shrank during the transient part of the test. Once the peak temperatures of the transient were reached, the maximum deformation of the insulation was achieved. This was accompanied by an increase in the effective thermal conductivity. A steady state condition was then reached below those peak temperatures.

After the test and the subsequent disassembly of the test fixture, observations and measurements of the insulation geometry were used to modify the 3D TD model. Figures 14 to 16 show these modifications.
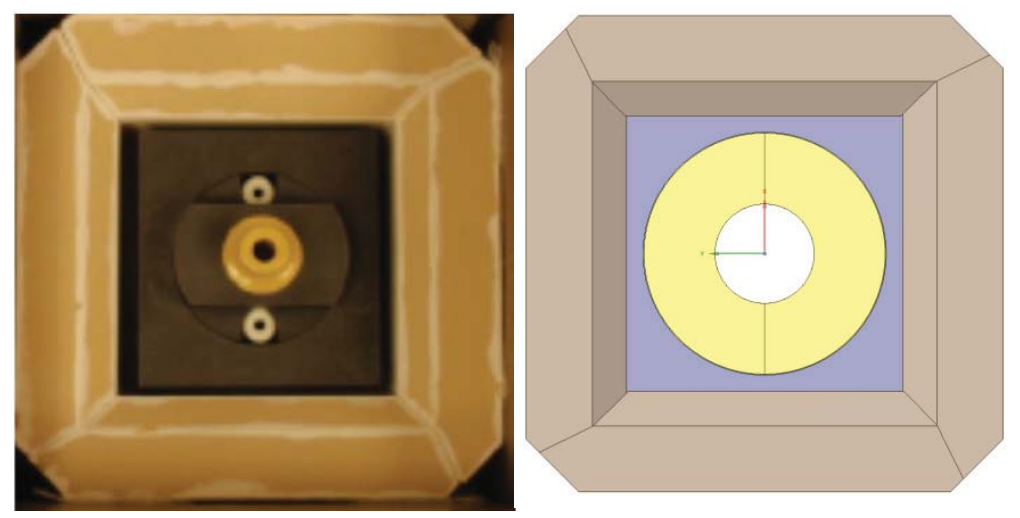

Figure 14. View of insulation for normal operation; before heat dump. 

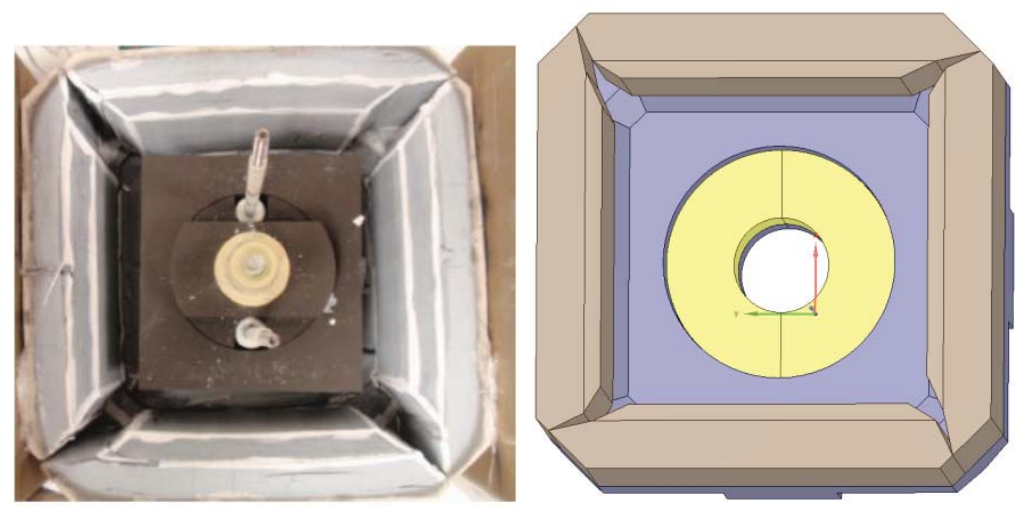

Figure 15. View of insulation for failed advanced Stirling convertor; after heat dump.

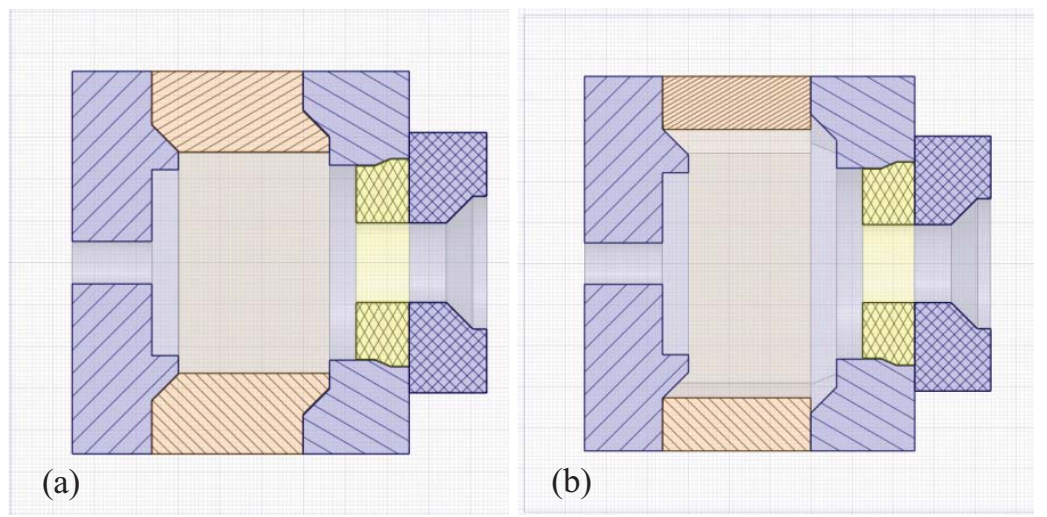

Figure 16. (a) Normal operation. (b) After heat dump and shrinking.

Modifications to the geometry for the post-heat-dump case included reducing the thickness around the side pieces and creating gaps at the corners. Measurements and photographs provided by LM were used for the modifications. Also, gaps were inserted between some of the pieces that had been in contact to approximate the lost conduction between those pieces. Measurements had not been provided for the exact size of those gaps (which were much less than the measured gaps). The infrared emissivity of the shrunken insulation was measured at the NASA Glenn Research Center, and this value was incorporated into the model.

The overall thermal conductivity of the Microtherm HT was adjusted until the model temperatures matched the test data. A single multiplier was applied in all three directions to the anisotropic thermal conductivity. The resulting value of the multiplier was 2.18. Figures 17 to 19 show the resulting temperatures for the post-heat-dump steady state condition of the ASRG. 


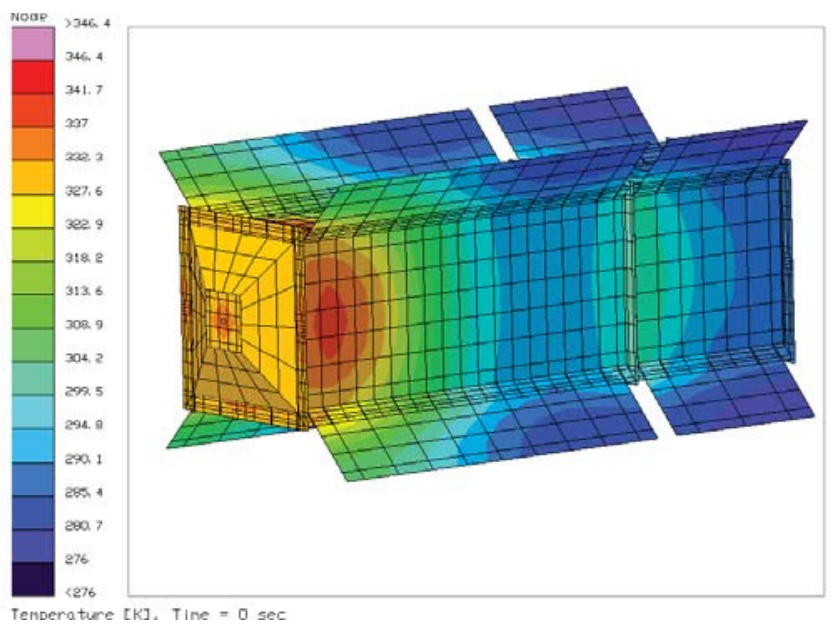

Figure 17. Outboard housing temperatures with failed advanced Stirling convertor.

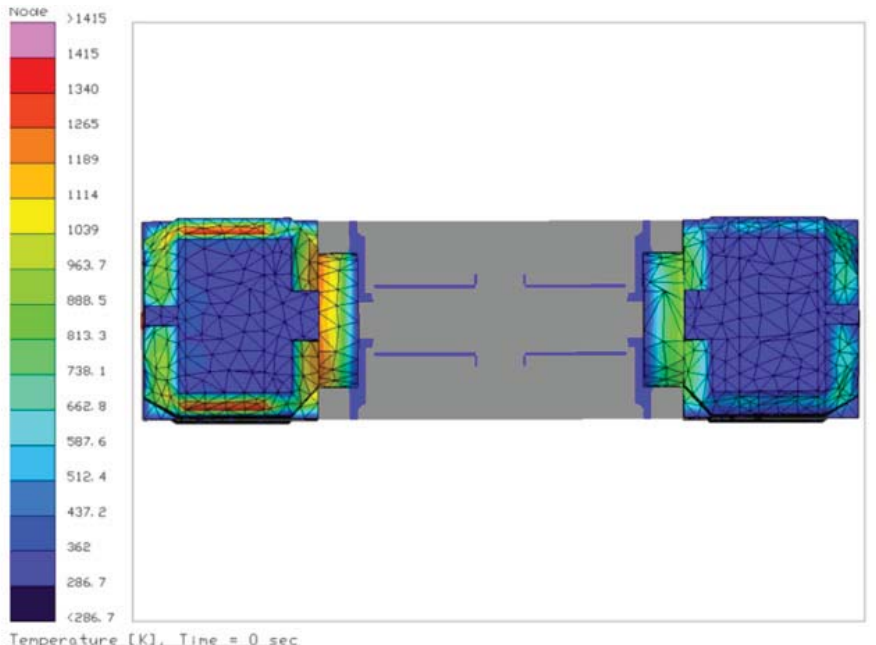

Figure 18. Insulation surface temperatures (failed advanced Stirling convertor on left).

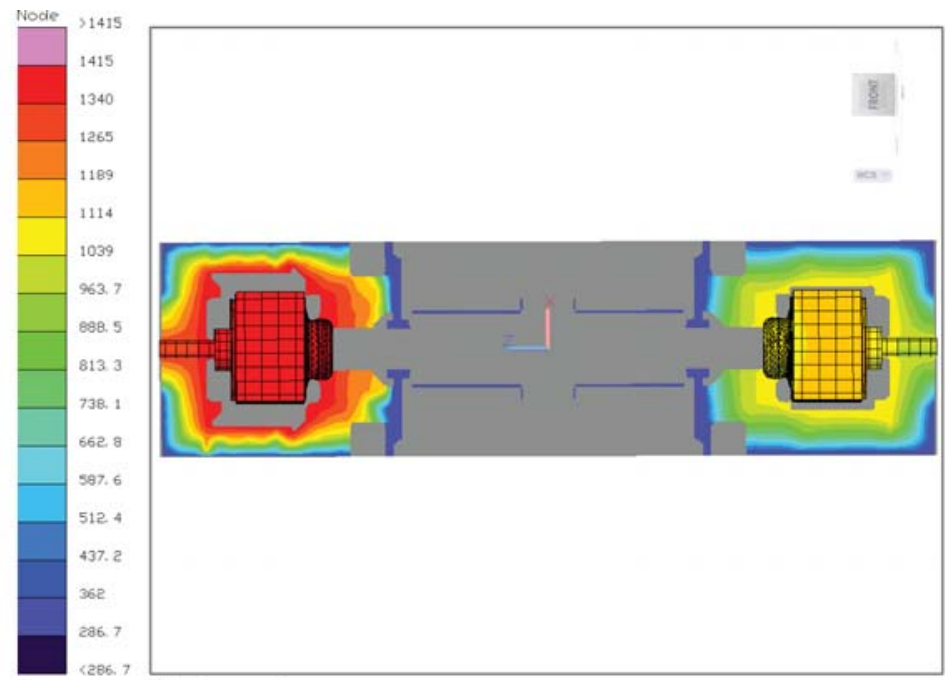

Figure 19. Insulation mid plane temperatures (failed advanced Stirling convertor on left). 
Despite the higher temperatures on the side of the housing with the failed ASC, the remaining ASC continued to operate with no degradation in performance.

With the TD model it was possible to analyze how the failed ASC and the deformed and shrunken insulation altered the heat flow through the hardware. The following flow charts (Figs. 20-21) show both the pre-heat-dump (normal operation) and post-heat-dump (with one failed ASC) heat flows through the various components.

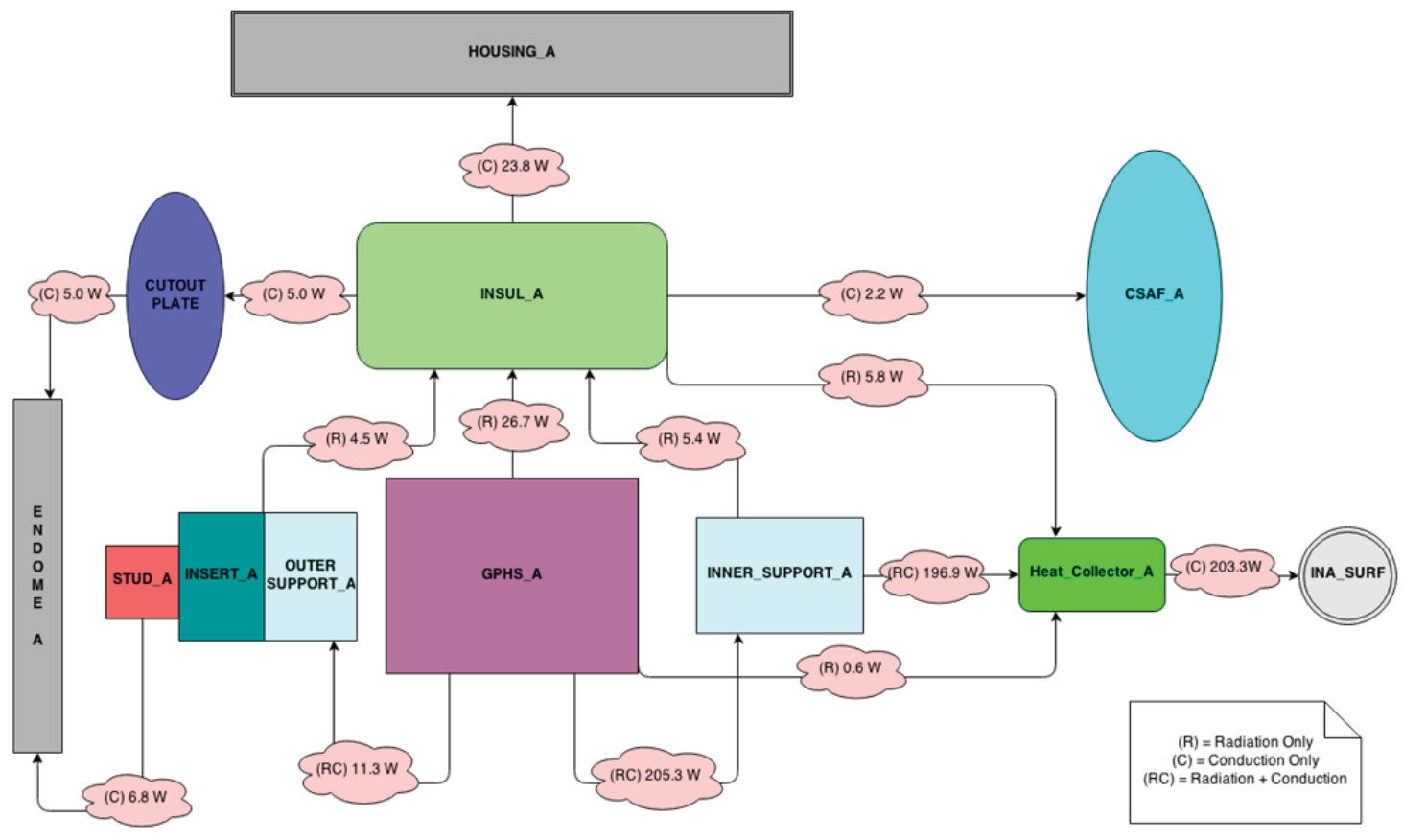

Figure 20. Heat flow; normal operation.

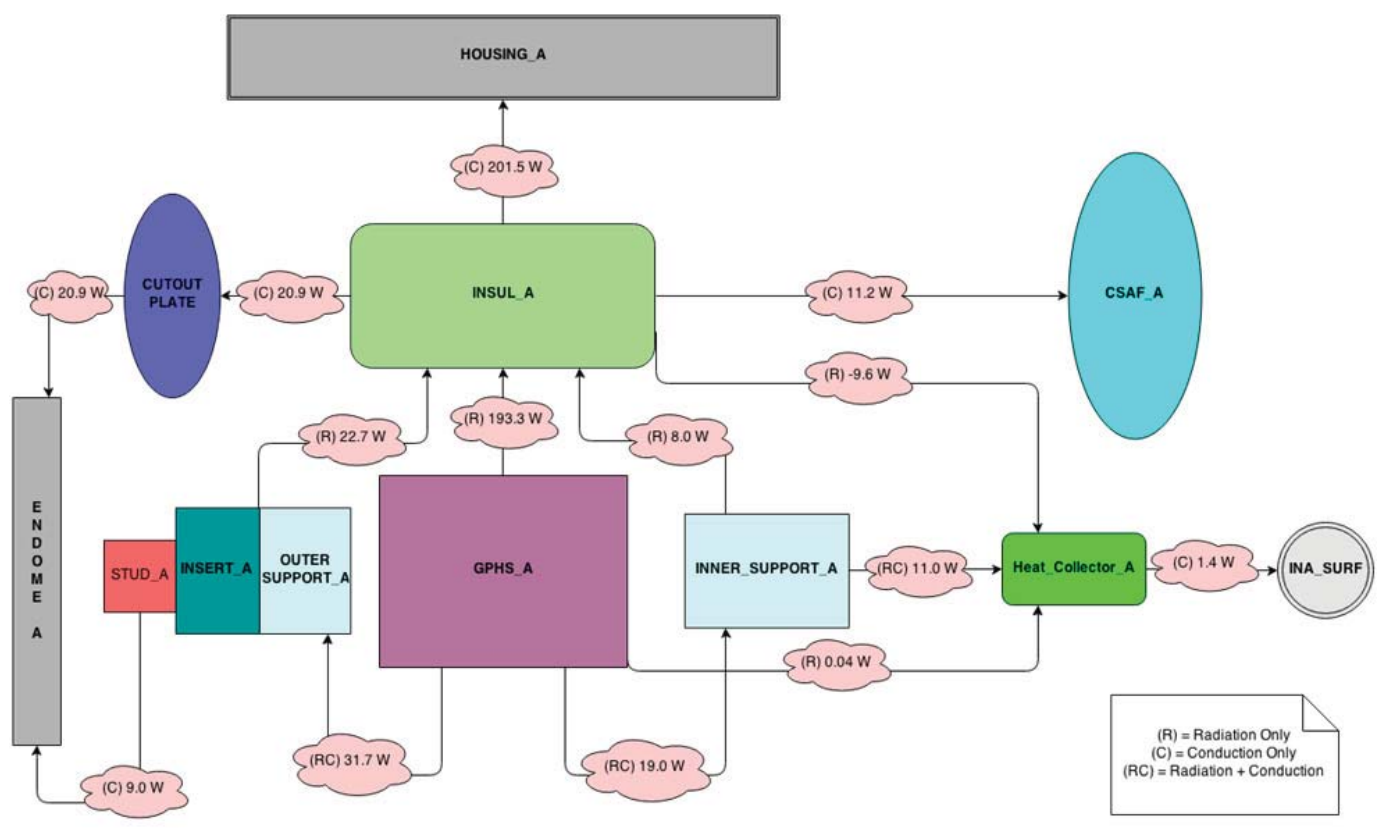

Figure 21. Heat flow; failed advanced Stirling convertor (ASC) after heat dump. (Geometry labeled "INA_SURF" represents ASC.) 
This analysis shows the degree to which the change in geometry and thermophysical properties accommodates the heat no longer flowing through the ASC. The heat through the insulation to the housing in the post-heat-dump scenario is nearly eight times that through the insulation during normal operations.

\section{Summary}

Recent thermal model results were reported for an Advanced Stirling Radioisotope Generator (ASRG). Auxiliary cooling system performance was reported for nominal conditions and for a Venus flyby scenario based on steady-state analysis. Steady-state results showed that $23.3 \mathrm{~W}$ of waste heat can be removed from the ASRG for the nominal case and that $189.4 \mathrm{~W}$ can be removed for the Venus flyby. The transient results were presented for a representative Venus flyby trajectory. Current model results show that, on the basis of steady-state results (the worst case), the alternator temperature increased $\sim 30{ }^{\circ} \mathrm{C}$ during the flyby. The transient model results show a $10^{\circ} \mathrm{C}$ increase. Some uncertainty concerning how fast the ASRG responds to environmental changes was addressed. The ASRG also was modeled mounted on a spacecraft with a sunshade, and the transient analysis results show that a sunshade can lower the ASRG $T_{c}$ by $\sim 20{ }^{\circ} \mathrm{C}$. Modification of the ASRG thermal model based on testing of a simulated failed ASC and the subsequent analysis shows that the resulting changes in heat flows are constrained to the region of the corresponding insulation block and that the performance of the remaining functional ASC is unaffected.

\section{Acknowledgments}

The authors thank June Zakrajsek and Lee Mason of NASA Glenn Research center for supporting this

effort under the Radioisotope Power System Program, and Duane Beach for providing advice and support for this modeling work.

\section{References}

1. Chan, J., Wood, J. G., and Schreiber, J. G., "Development of Advanced Stirling Radioisotope Generator for Space Exploration," Space Technology and Applications International Forum (STAIF), Feb. 11-15, 2007.

2. Lewandowski, E. J., and Schreiber, J. G., "Testing to Characterize the Advanced Stirling Radioisotope Generator Engineering Unit," 8th International Energy Conversion Engineering Conference (IECEC), Nashville, TN, July 25-28, 2010.

3. Wang, X. Y., Fabanich, W. A., Schmitz, P. C., "Advanced Stirling Radioisotope Generator (ASRG) Thermal Power Model in Thermal Desktop SINDA/FLUINT Analyzer," 10th International Energy Conversion Engineering Conference (IECEC), Atlanta, Georgia, 2012.

4. PIR 093-ASRG Auxiliary Cooling Loop (ACL) Concept and Analysis, Lockheed Martin, Jan. 2010.

5. PIR 196-ASRG Transient Thermal Analysis Model, Lockheed Martin, May 2012.

6. PIR 0110_Emergency Heat Dump Test Results and Correlation, Lockheed Martin, July 2010. 